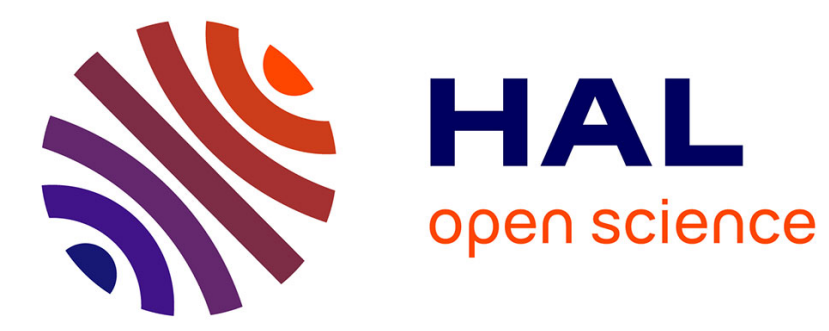

\title{
Using damage mechanics to simulate the behavior of various reinforced concrete walls submitted to earthquake loading
}

\author{
Panagiotis Kotronis, J. Mazars
}

\section{- To cite this version:}

Panagiotis Kotronis, J. Mazars. Using damage mechanics to simulate the behavior of various reinforced concrete walls submitted to earthquake loading. Journal of the Mechanical Behavior of Materials, 2005, 16 (1-2), pp.75-83. 10.1515/JMBM.2005.16.1-2.75 . hal-01007415

\section{HAL Id: hal-01007415 https://hal.science/hal-01007415}

Submitted on 30 Oct 2019

HAL is a multi-disciplinary open access archive for the deposit and dissemination of scientific research documents, whether they are published or not. The documents may come from teaching and research institutions in France or abroad, or from public or private research centers.
L'archive ouverte pluridisciplinaire HAL, est destinée au dépôt et à la diffusion de documents scientifiques de niveau recherche, publiés ou non, émanant des établissements d'enseignement et de recherche français ou étrangers, des laboratoires publics ou privés. 


\title{
Using Damage Mechanics to Simulate the Behavior of Various Reinforced Concrete Walls Submitted to Earthquake Loading
}

\author{
P. Kotronis and J. Mazars \\ Laboratoire Sols Solides Structures (C.N.R.S./I.N.P.G./U.J.F.) \& R.N.V.O. \\ Domaine universitaire B.P. 53, F-38041 Grenoble Cedex 9 - France \\ email: panagiotis.kotronis@hmg.inpg.fr
}

\section{SUMMARY}

A damage model and different simplified numerical strategies are proposed to simulate the behavior of reinforced concrete (RC) walls submitted to earthquake ground motions. For RC walls controlled primarily by bending the 2D Euler beam theory is adopted. When dealing with structures with a small slenderness ratio we use the Equivalent Reinforced Concrete model. Finally, for 3D problems a multifiber Timoshenko beam element with higher order interpolation functions has been developed. For each case, a comparison with experimental results shows the good basis of the approach.

\section{INTRODUCTION}

Simulating the nonlinear behavior of reinforced concrete (RC) walls submitted to severe ground motion is an important problem for the engineering community. Nonlinear dynamic analysis of complex civil engineering structures based on a detailed finite element model requires large-scale computations and handles delicate solution techniques. The need to perform parametric studies and the stochastic nature of the input accelerations impose simplified numerical modeling that reduces computational cost. However, constitutive models for concrete under cyclic loading have to be able to take into account some complex phenomena such as decrease in material stiffness due to cracking, stiffness recovery which occurs at crack closure and inelastic strains concomitant to damage. An optimum idealization is then needed, i.e. one that is sufficiently fine and yet not too costly.

To simulate the behavior of concrete under cyclic loading we use a damage model with two scalar damage variables, one for damage in tension and the other for damage in compression. Unilateral effect and stiffness recovery are also included. For the usual RC wall whose behavior is controlled primarily by bending 
we choose the classical 2D Euler beam theory. Beams are divided in several layers where uniaxial constitutive relationships for steel and concrete are used. When dealing with structures with a slenderness ratio far from the classical beam theory a more reliable representation of shear deformations and shear stresses has to be provided. One possibility in that respect - always within the family of simplified modeling strategies - is to use the Equivalent Reinforced Concrete model that permits the use of lattice meshes for concrete and reinforcement bars. Finally for 3D problems, a multifiber Timoshenko beam element with higher order interpolation functions has been developed. Comparison with experimental results of RC walls tested on shaking table and reaction wall shows, for each case, the good basis but also the limitations of the approach.

\section{A DAMAGE MODEL FOR CONCRETE UNDER CYCLIC LOADING}

A constitutive model for concrete under cyclic loading ought to take into account some observed phenomena, such as decrease in material stiffness due to cracking, stiffness recovery which occurs at crack closure and inelastic strains concomitant to damage. To simulate this behavior we use a damage model with two scalar damage variables one for damage in tension and one for damage in compression /8/. Unilateral effect and stiffness recovery (damage deactivation) are also included. Inelastic strains are taken into account thanks to an isotropic tensor. The total strain is given by:

$$
\begin{aligned}
& \boldsymbol{\varepsilon}=\boldsymbol{\varepsilon}^{\mathbf{e}}+\varepsilon^{\text {in }} \\
& \varepsilon^{\mathrm{e}}-\frac{\langle\boldsymbol{\sigma}\rangle_{+}}{E\left(1-D_{l}\right)}+\frac{\langle\boldsymbol{\sigma}\rangle_{-}}{E\left(1-D_{2}\right)} \div \frac{v}{E}(\boldsymbol{\sigma}-\operatorname{Tr}(\boldsymbol{\sigma}) l) \\
& \varepsilon^{\text {in }}-\frac{\beta_{1} D_{1}}{E\left(1-D_{l}\right)} \frac{\partial f(\boldsymbol{\sigma})}{\partial \boldsymbol{\sigma}}+\frac{\beta_{2} D_{2}}{E\left(1-D_{2}\right)} 1 \\
& \operatorname{Tr}(\boldsymbol{\sigma}) \in[0,+\infty) \quad \rightarrow \frac{\partial f(\boldsymbol{\sigma})}{\partial \boldsymbol{\sigma}}=1 \\
& \operatorname{Tr}(\boldsymbol{\sigma}) \in\left[-\sigma_{f}, 0\right) \rightarrow \frac{\partial f(\boldsymbol{\sigma})}{\partial \boldsymbol{\sigma}}=\left(1-\frac{\operatorname{Tr}(\boldsymbol{\sigma})}{\sigma_{f}}\right) 1 \\
& \operatorname{Tr}(\boldsymbol{\sigma}) \in\left(-\infty,-\sigma_{f}\right) \rightarrow \frac{\partial f(\boldsymbol{\sigma})}{\partial \boldsymbol{\sigma}}=0.1
\end{aligned}
$$

with $\varepsilon^{\varepsilon}$ elastic strains and $\varepsilon^{\text {in }}$ inelastic strains. 1 denotes the unit tensor and $\operatorname{Tr}(\boldsymbol{\sigma})=\sigma_{i j} \cdot f(\sigma)$ is the crack closure function and $\sigma_{f}$ the crack closure stress. $\langle.\rangle_{+}$denotes the positive part of a tensor. $E$ is the 
initial Young's modulus and $v$ the Poisson ratio. $D_{1}$ and $D_{2}$ are respectively the damage variables for traction and compression. $\beta_{1}$ and $\beta_{2}$ are material constants. Damage criteria are expressed as $f_{t}=Y_{t}-Z_{l}(l=1$ for tension or 2 for compression, $Y_{i}$ is the associated force to the damage variable $D_{l}$ and $Z_{l}$ a threshold dependent on the hardening variables). The evolution laws for the damage variables $D_{1}$ are written as:

$$
D_{l}=I-\frac{1}{1+\left[A_{i}\left(Y_{i}-Y_{0 i}\right)\right]^{B_{i}}}
$$

$Y_{0 i}=$ initial elastic threshold $\left(Y_{0}=Z_{l}\left(D_{l}=0\right)\right)$ and $A_{\imath}, B$, material constants. Fig. 1 gives the stressstrain response of that model for a uniaxial traction-compression loading.

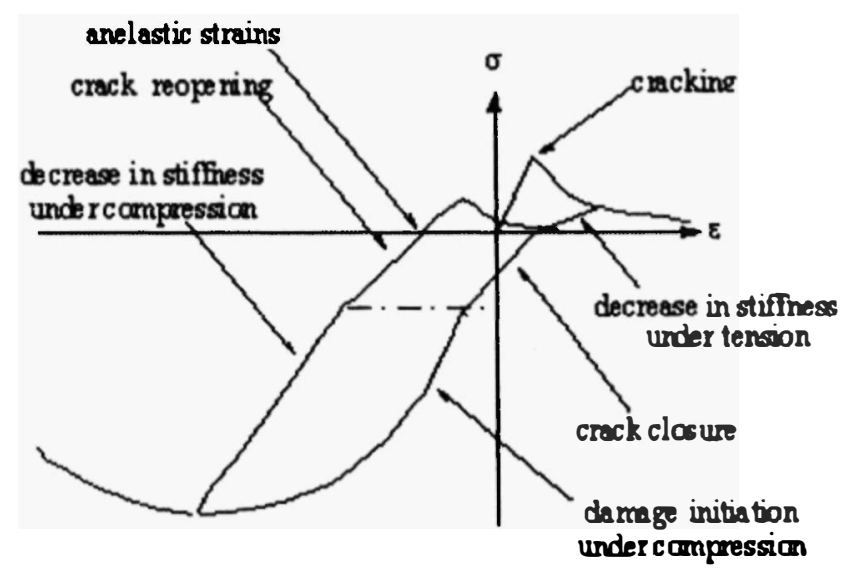

Fig. 1: Uniaxial response of concrete damage model for cyclic loading

\section{MODELING OF A RC BEARING WALL}

A RC bearing wall is one whose behavior is controlled primarily by bending. A simplified way to model such a structure is to use $2 \mathrm{D}$ multilayered Euler beam elements and concentrated masses at specific points (Fig. 2). Uniaxial constitutive laws for concrete and steel are attributed at each layer and seismic loading is applied as an input motion at the base. Dynamic analysis for earthquake ground is done according to the classical Newmark scheme. The discrete set of equations obtained is further solved by an iterative Newton solution procedure, where at each iteration the secant stiffness matrix is used. 


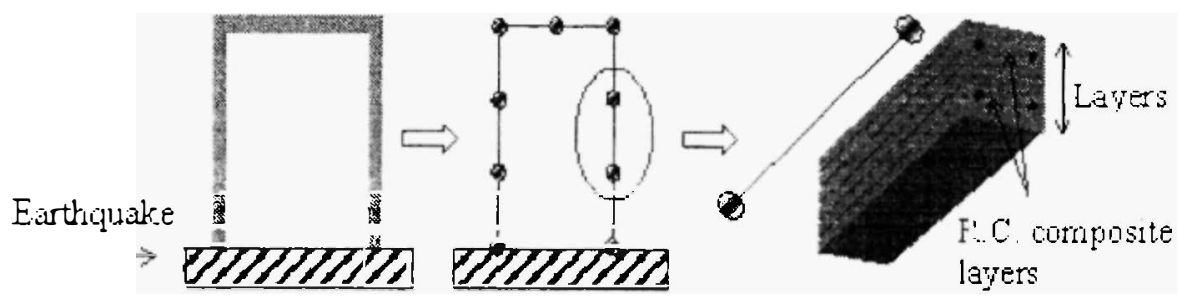

Fig. 2: Multilayered Beam Formulation for RC Structures

This approach has been used to model the non linear behavior of the CAMUS III specimen tested on the shaking table at CEA Saclay $12 /$. The $1 / 3^{\text {rd }}$ scaled model is composed of two parallel 5 -floor reinforced concrete walls without opening linked by 6 square floors (Fig. 3) A highly reinforced footing allows the anchorage to the shaking table. The mock-up is loaded with horizontal acceleration signals parallel to the walls in their own plane. The dynamic tests have been performed until collapse of the mock-up. By collapse we mean the appearance of significant cracks on the concrete walls and important plastic strain with possible failure of some bars of the vertical reinforcing steel.
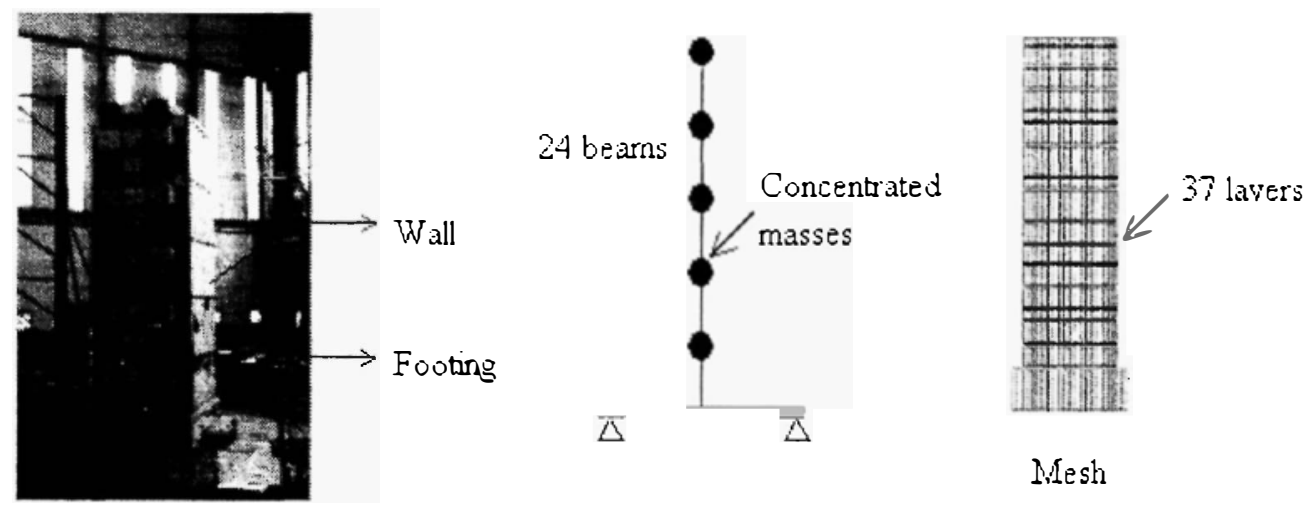

Fig. 3: CAMUS III specimen and numerical model

The 2-D numerical model adopted represents each wall as a cantilever beam (Fig. 3). The wall is divided into 24 Euler beam elements with 37 layers each. Concentrated masses are introduced at each floor. A single wall is considered. The uniaxial version of the damage constitutive law is used for concrete and a classical ID plasticity model with hardening for steel. No calibration of the numerical results has been made, making the comparison with the experimental results similar to the one of a "blind simulation". Results compared in terms of global and local variables show good agreement (Figs. 4-5). Detailed information and interpretation of the numerical results can be found in $/ 1 /, / 6 /$. 


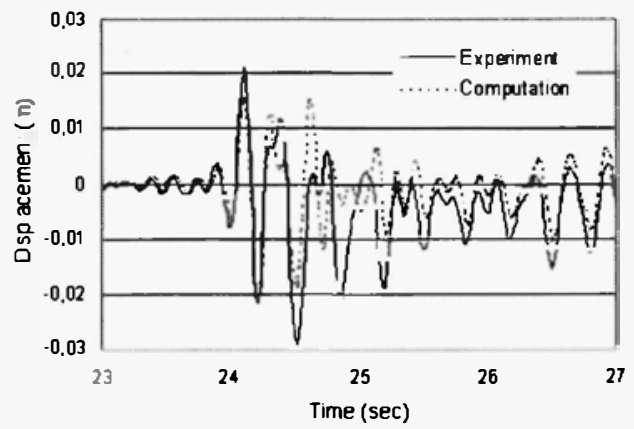

Fig. 4: CAMUS III - Displacement time history (Melendy Ranch signal)

(a)

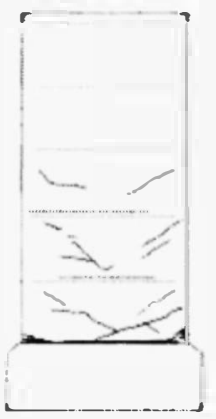

(b)

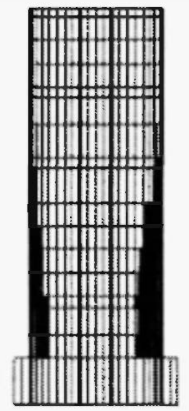

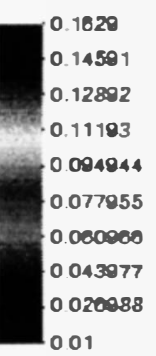

Fig. 5: CAMUS Ill - Cracking of the wall at the end of the experiment (a) Damage pattern due to compression (b) due to tension (c).

\section{MODELING OF A RC SHEAR WALL}

A RC shear wall is one that its behavior is controlled primarily by shear. For structures with small slenderness ratio (less than 1) a model based on beam theory has difficulties in reproducing satisfactorily the shear deformations and stresses. An alternative simplified method is the so-called Equivalent Reinforced Concrete (ERC) model /7, 9/. The model uses a lattice mesh for predicting the non-linear behaviour of shear walls under dynamic loading and is inspired on the Framework Method /5/. The basic idea consists of using the patterns of the Framework Method coupled with damage mechanics in a non-linear context and for a nonhomogenous material. The main assumptions of the proposed strategy are (Fig. 6):

a) An elementary volume of reinforced concrete (EV) can be separated into a concrete element (C) and a horizontal and a vertical reinforcement bar $\left(S_{H}\right.$ and $S_{V}$ respectively). Concrete and steel are then modeled separately using two different lattices. 
b) The sections of the bars simulating concrete have been derived directly from the Framework Method. The damage model in its ID formulation is used for simulating the non-linear behaviour of concrete.

c) A lattice composed by horizontal and vertical bars coupled with a uniaxial plasticity model with or without hardening simulates steel. The section and position of the bars coincide with the actual section and position of the reinforcement. In order to simplify the mesh the method of distribution is used, where the sections of bars are defined proportional to a corresponding surface area. In that way the mesh is independent of the geometry of the specimens.

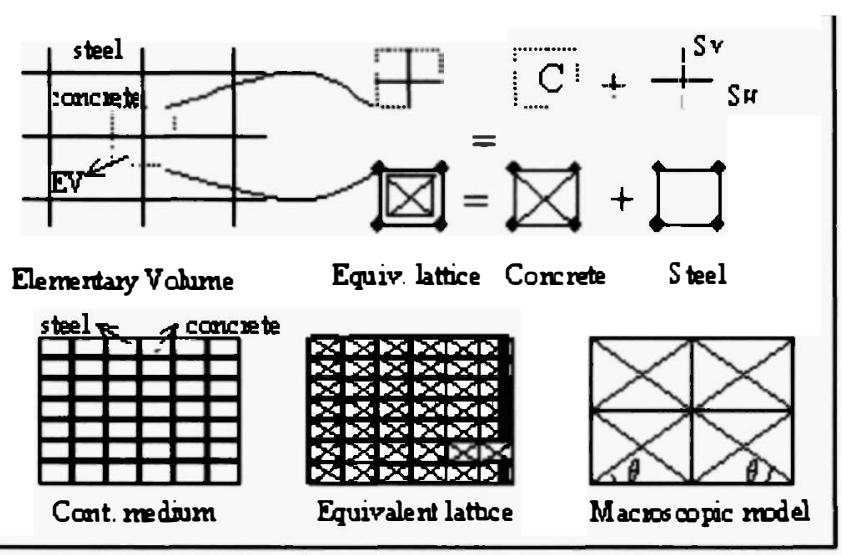

Fig. 6: The Equivalent Reinforced Concrete model

The performance of the ERC model was evaluated on the NUPEC specimen (a shear wall with a slenderness ratio equal to 0.7 ) tested on the shaking table at the Tadotsu Engineering Laboratory /10/.The specimen was excited with horizontal acceleration signals parallel to its plane. The rotation at the top of the mock-up was free. A zoom at the last sequence (50 - $53 \mathrm{sec}$, Fig. 7) shows that the ERC model predicts correctly the global behaviour of the structure even under severe loading (just before collapse). Detailed information and interpretation of the numerical results can be found in $/ 6 /$.
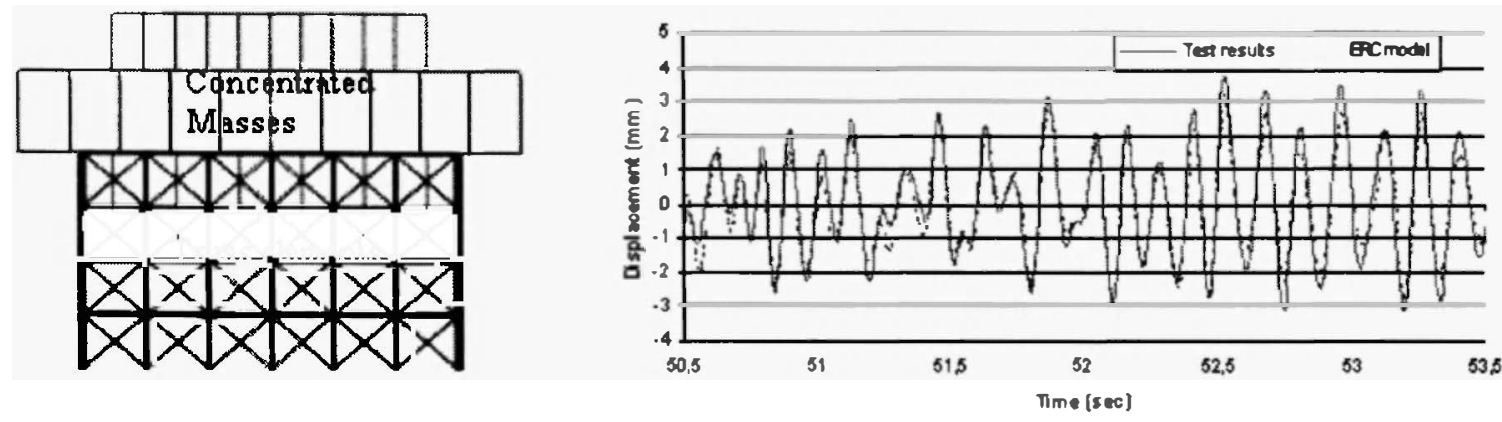

Fig. 7: NUPEC specimen - Concrete mesh and displacement time history analysis 


\section{3D MODELING OF A RC WALL}

In order to simulate, in a simplified manner, the 3D non linear behavior of a $\mathrm{RC}$ wall under dynamic loading, a 3D multifiber Timoshenko beam element has been recently developed $/ 6 /$. The user can define at each fiber a material and the appropriate 3D constitutive law. The element uses higher order interpolation functions to avoid any shear locking phenomena $/ 3 /$ that depend on the material's properties and are calculated only once, for the first increment. Details about the section stiffness and mass matrices can be found in $/ 4 /$. The implementation was made in the library FEDEAS of the finite element code FEAP/12/.

In order to validate the performance of the proposed numerical strategy the experimental results of a RC U-shaped wall tested pseudodynamically at the reaction wall of the ELSA laboratory at JRC Ispra were used /11/. The $3 \mathrm{~m}$. height specimen is composed of the U-shaped wall, the inferior slab and the superior slab. The superior slab is used as the horizontal load application point while vertical post-tensioning bars apply a normal force. These bars are disposed in a way that the force is applied close to the inertial centre in order to avoid spurious bending on the structure. Torsion is prohibited during the tests. The wall is loaded in both directions according to the butterfly path presented in Fig. 8.
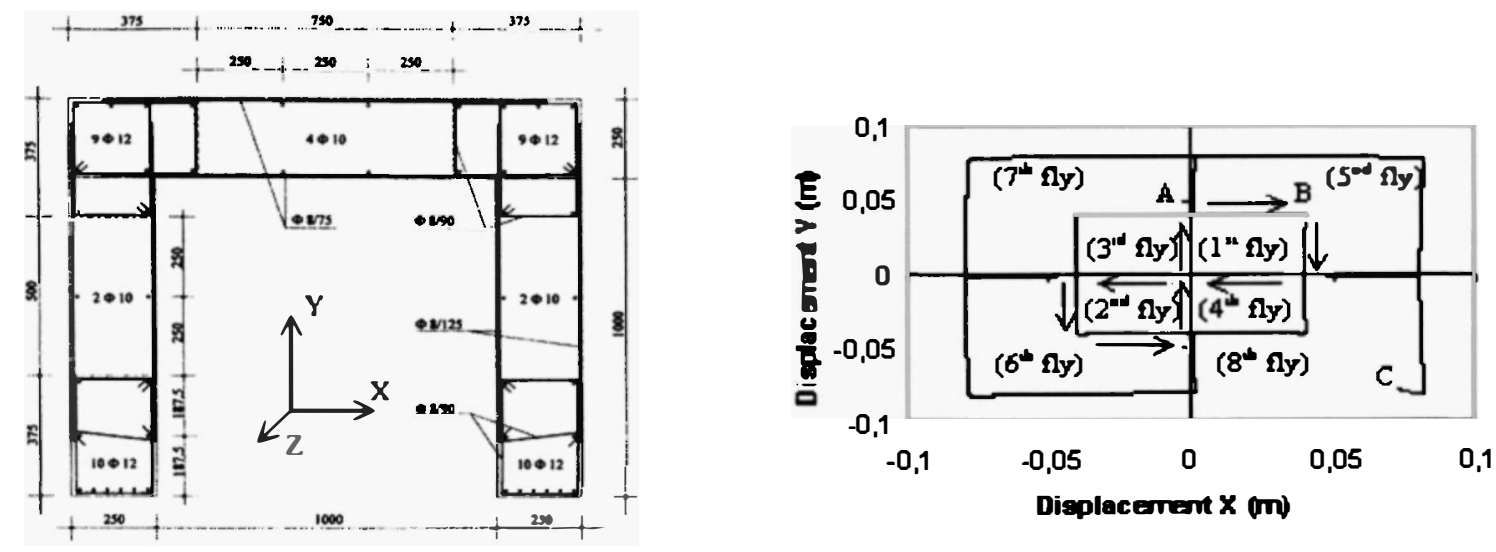

Fig. 8: U-shaped wall - Description of the specimen and loading history

Eleven multi-fiber Timoshenko beam elements are used to model the wall; 177 fibers simulate concrete and 46 fibers steel. Two gauss points are considered at each element. The base slab is not simulated and the wall is considered fixed at the base. The superior slab is linear and rotation of the upper part is prohibited in order to reproduce correctly the boundary conditions of the test. For this first series of calculations ID constitutive laws are used for concrete and steel. Comparison of numerical and experimental results for the eight flies of loading are represented in Fig. 9 (the letters A, B, C refer to Fig. 8) and one can observe the ability of the model to simulate correctly the global behaviour of the mock-up in terms of displacements. 


\section{CONCLUSIONS}

Damage mechanics is a powerful tool for modeling the non linear behavior of different type of RC walls submitted to earthquake ground motions. Combined with simplified modeling strategies, as the ones proposed throughout this work, one can simulate the global and local behaviour of structures in terms of displacements, forces and damage distribution patterns. Calculation is not time consuming and the proposed methods allow for parametrical studies. Further work is in progress towards the development and implementation of a $3 \mathrm{D}$ robust constitutive model for concrete.
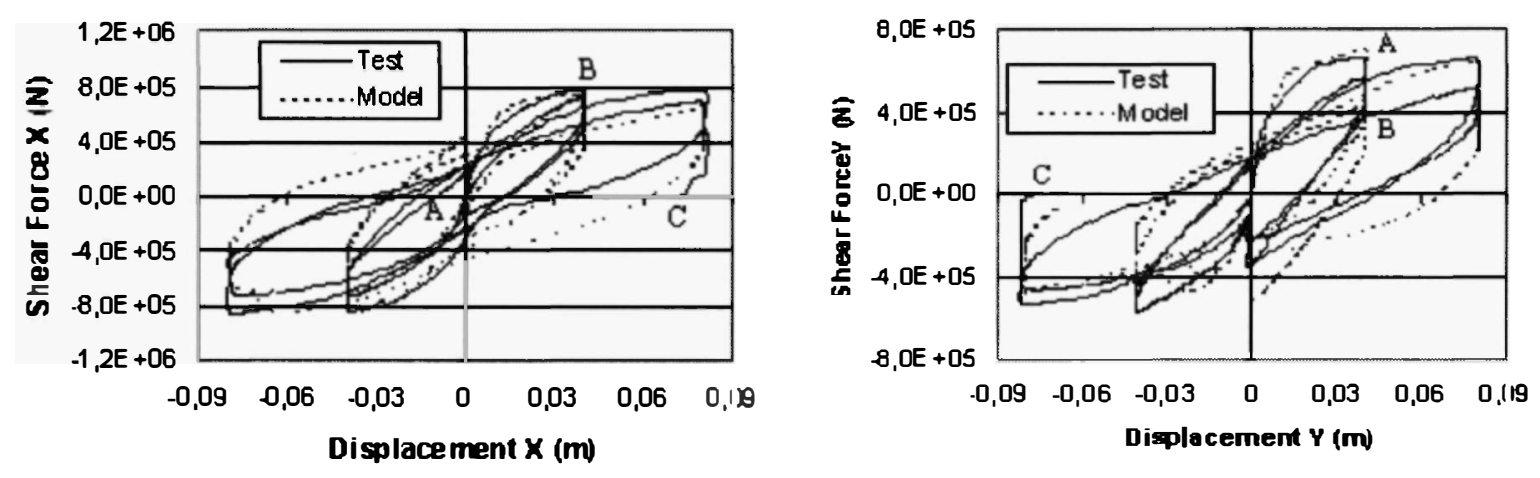

Fig. 9: U-shaped wall - Experimental versus numerical results

\section{ACKNOWLEDGEMENTS:}

The present work was granted from the European program ICONS [1].

\section{REFERENCES}

1. CAFEEL-ECOEST/ICONS., Thematic report N.S. Shear Walls Structures, J.M. Reynouard and M.N. Fardis (Eds.), September, 2001.

2. D. Combescure and Th. Chaudat, ICONS European program seismic tests on R/C bearing walls. CAMUS IIl specimen, Rapport DMT, SEMT/EMSI/RT/00-014/A, CEA Saclay, 2000.

3. Z. Friedman and J.B. Kosmatka, An improved two-node Timoshenko beam finite element. Computers and Structures, 47 (3), 473-481 (1993).

4. J. Guedes, P. Pégon and A. Pinto, A fibre Timoshenko beam element in CASTEM 2000, Special publication Nr. I.94.3I, JRC, I-21020, Ispra, Italy, 1994. 
5. A. Hrennikoff, Solution of problems of elasticity by the Framework Method, J. of Applied Mechanics, Al69-A175 (1941).

6. P. Kotronis, Cisaillement dynamique de murs en beton arme. Modeles simplifies 2D et 3D, These de doctorat, ENS Cachan, 2000.

7. P. Kotronis, J. Mazars and L. Davenne, The equivalent reinforced concrete model for simulating the behavior of shear walls under dynamic loading. Engineering Fracture Mechanics., 7-8, 1085-1097 (2003).

8. C.L. La Borderie, Phenomenes unilateraux dans un materiau endommageable: modelisation et application à l'analyse des structures en beton, These de doctorat, Universite Paris 6, 1991.

9. J. Mazars, P. Kotronis and L. Davenne, A new modelling strategy for the behaviour of shear walls under dynamic loading, Earthquake Engineering and Structural Dynamics, 31 (4), $937-954$ (2002).

10. OECD, Seismic shear wall ISP. NUPEC'S seismic ultimate dynamic response test, Comparison report, $O C D E / G D(96) / 88,1996$.

11. P. Pegon, C. Plumier, A. Pinto, J. Molina, P. Gonzalez, P. Tognoli and O. Hubert, U-shaped-wall: Description of the experimental set-up, Report JRC, Ispra, 2000.

12. R.L. Taylor, FEAP: A finite element analysis program, version 7.3 manual, University of California, Berkeley, 2000. 